\title{
A Comparison of Vital Capacity between Normal Weight and Underweight Women in their 20s in South Korea
}

\author{
Jin-Tae Han, PhD, PT ${ }^{1)}$, SAnG-Yeol Lee, PhD, PT ${ }^{1)}$ \\ 1) Department of Physical Therapy, Kyungsung University: 314-79 Daeyeon-3dong, Nam-gu, Busan, \\ 608-736, Republic of Korea.E-mail: sjslh486@hanmail.net
}

\begin{abstract}
Purpose] The aim of this study was to compare the vital capacity (FVC, FEV, MVV) of normal and underweight women in their 20s. [Subjects] Thirty-four healthy non-smoking young women (age 20-25 years) participated in this study. [Methods] Based on body mass index (BMI), subjects were divided into two groups: the normal weight group $(\mathrm{n}=18,18.5<\mathrm{BMI} \leq 25.0)$ and the underweight group $(\mathrm{n}=16, \mathrm{BMI} \leq 18.5)$. FVC, $\mathrm{FEV}_{1}$ and $\mathrm{MVV}$ were measured using a respiratory function instrument, Spiropalm (A-M systems, USA), which fulfills the American Thoracic recommendation for diagnostic spirometry. The independent t-test was used to compare vital capacities (FVC, $\mathrm{FEV}_{1}$ and MVV) between the normal and underweight group. [Results] The underweight group had significantly lower $\mathrm{FVC}$ and $\mathrm{FEV}_{1}$ than the normal weight group. MVV of the underweight group was also lower than that of the normal weight group, but the difference was not significant. [Conclusion] Our results indicate that low body weight is related to reduction of vital capacity in women. These results also suggest that the maintenance of adequate body weight may be important for improving the vital capacity of women.

Key words: BMI, Underweight, Vital capacity
\end{abstract}

(This article was submitted Nov. 14, 2011, and was accepted Dec. 8, 2011)

\section{INTRODUCTION}

A lot of studies have researched relationships with obesity $^{1-3)}$. Formiguera and Cantón reported that two of most the common respiratory disturbances found in obesity are obstructive sleep apnea and obesity hypoventilation syndrome ${ }^{4}$. Underweight women are also at risk of various health disorders.

In South Korea, the National Statistical Office ${ }^{5)}$ estimates that $4.64 \%$ of those aged 20 and above are underweight. Recently, many young women have been going on diets aiming for a slim body. However, an unhealthy diet may lead to weakness, frailty, functional impairment, anorexia and bulimia, and ultimately, death ${ }^{6,7)}$. Despite the health risks that being underweight can pose, there is no study in the literature reporting on the functional problems of underweight women ${ }^{8)}$, particularly, respiratory function.

Spirometry is a physical test that measures how an individual inhales or exhales volumes of air as a function of time and is a pulmonary function test that measures forced vital capacity (FVC), forced expiratory volume in $1 \mathrm{~s}\left(\mathrm{FEV}_{1}\right)$ and maximum voluntary ventilation (MVV). FVC is the maximum volume of air exhaled with maximally forced effort from a maximal inspiration, and $\mathrm{FEV}_{1}$ is the volume of air expelled during the first second of maximal expiration ${ }^{9}$. MVV is the maximum volume of air a subject can breathe over a specified period of time (12 $\mathrm{s}$ for normal subjects). MVV demonstrates the mechanical factors of breathing and provides information regarding increase in airway resis- tance, reduced compliances or respiratory muscle force ${ }^{10,11)}$.

The aim of this study was to compare the vital capacities (FVC, $\mathrm{FEV}_{1}, \mathrm{MVV}$ ) of normal and underweight women in their 20s, and the results suggest that the assessment of the respiratory function in women who are underweight is clinically important.

\section{SUBJECTS AND METHODS}

Thirty-four healthy non-smoking young women (age 20-25 years) participated in this study. Based on body mass index (BMI), subjects were divided into two groups: the normal weight group $(\mathrm{n}=18,18.5<\mathrm{BMI} \leq 25.0)$ and the underweight group $(\mathrm{n}=16, \mathrm{BMI} \leq 18.5)$. BMI is routinely used to estimate underweight or the degree of obesity ${ }^{12,13)}$, and it is calculated as body weight divided by body height squared $\left(\mathrm{kg} / \mathrm{m}^{2}\right)$. All subjects read and signed consent forms, in accordance with the ethical standards of the Declaration of Helsinki.

$\mathrm{FVC}, \mathrm{FEV}_{1}$ and MVV were measured using a respiratory function instrument, Spiropalm (A-M systems, USA), which fulfills the American Thoracic recommendation for diagnostic spirometry ${ }^{14)}$. To measure the FVC and $\mathrm{FEV}_{1}$, the subjects are asked to take a rapid full inspiration through the mouthpiece; then, without hesitation, perform an expiration with maximum force until no more gas could be expelled, followed by a quick maximum inspiration. To measure MVV, at least three resting tidal breaths should be obtained. The subjects followed that performance of the procedure by 
breathing as rapidly and deeply as possible for 12 seconds ${ }^{10)}$. Prior to the tests, the required maneuvers were demonstrated by a trained operator. All maneuvers were performed in the sitting position and repeated as many as times as necessary until two acceptable maneuvers were obtained.

The independent t-test was used to compare the vital capacities (FVC, $\mathrm{FEV}_{1}$ and $\mathrm{MVV}$ ) of the normal and the underweight groups. Data are expressed as means $\pm \mathrm{SD}$, and $\mathrm{P}$-values less than 0.05 were considered significant.

\section{RESULTS}

The subjects' characteristics are shown in Table 1. Age and height were similar in the two groups. However, when compared with the normal weight group, the underweight group had significantly lower body weight and BMI.

Comparisons of FVC, $\mathrm{FEV}_{1}$ and MVV between the normal and underweight groups are shown in Table 2. The underweight group showed significantly lower FVC and $\mathrm{FEV}_{1}$ than the normal weight group $(\mathrm{p}<0.05)$. MVV of the underweight group was also lower than that of the normal weight group; however, the difference was not significant $(\mathrm{p}>0.05)$.

\section{DISCUSSION}

The purpose of this study was to elucidate whether there is an association between being underweight and the vital capacity. Being underweight has been linked to increased morbidity and mortality compared with having a BMI within the normal range ${ }^{15}$. A low BMI may be a reflection of a state of malnourishment where the body has fewer reserves, cannot react to stress appropriately, and may have a weakened immune system ${ }^{16}$. Muscloskeletal consequences of being underweight include less muscle mass, less soft tissue, and greater probability of osteoporosis ${ }^{16,17)}$.

BMI can be easily measured and it is therefore used frequently in large-scale epidemiologic studies ${ }^{18)}$. BMI was also used to classify the groups in this study. A limitation of BMI is that it does not distinguish between fat mass and muscle mass, which have opposite effects on pulmonary function $^{19,20)}$.

To measure the vital capacity in this study, a spiropalm was used. Spirometry is a pulmonary function test that helps to prevent, identify and quantify respiratory disorders as well as responses to therapy. In addition to its use in clinical case management, spirometry has become a routine examination in respiratory, occupational, and sports medicine as well as public health screening. However, it is necessary to consider that spirometry reference values can vary according to gender, age, height, race, technical factors and weight ${ }^{21)}$.

In the results, $\mathrm{FVC}$ and $\mathrm{FEV}_{1}$ of the underweight group were lower than those of the normal group, a result similar to those of some previous studies ${ }^{21}$. We believe that these results arise from muscle weakness and a reduction of pulmonary volume in the underweight group. However, MVV of the underweight group was no different from that of the normal weight group. In a previous study, MVV of males was higher than that of females ${ }^{11)}$, but there was no
Table 1.

\begin{tabular}{lcc}
\hline Variable & $\begin{array}{c}\text { Underweight } \\
(\mathrm{n}=16)\end{array}$ & $\begin{array}{c}\text { Normal weight } \\
(\mathrm{n}=18)\end{array}$ \\
\hline Age $(\mathrm{yr})$ & $21.7 \pm 1.7$ & $21.2 \pm 0.4$ \\
Height $(\mathrm{cm})$ & $157.7 \pm 2.7$ & $160.0 \pm 5.5$ \\
Weight $(\mathrm{kg}) * *$ & $44.7 \pm 3.3$ & $52.7 \pm 7.5$ \\
BMI $\left(\mathrm{kg} / \mathrm{m}^{2}\right) * *$ & $17.8 \pm 1.4$ & $20.6 \pm 3.3$ \\
\hline
\end{tabular}

** $<<0.01$, BMI: body mass index

Table 2. Comparison of vital capacity between normal and underweight group

\begin{tabular}{lcc}
\hline Variable & $\begin{array}{c}\text { Underweight } \\
(\mathrm{n}=16)\end{array}$ & $\begin{array}{c}\text { Normal weight } \\
(\mathrm{n}=18)\end{array}$ \\
\hline $\mathrm{FVC}(\mathrm{L}) * *$ & $2.5 \pm 0.2$ & $3.0 \pm 0.2$ \\
$\mathrm{FEV}_{1}(\mathrm{~L}) *$ & $2.0 \pm 0.3$ & $2.4 \pm 0.5$ \\
$\mathrm{MVV}(\mathrm{L} / \mathrm{min})$ & $75.5 \pm 17.8$ & $87.4 \pm 17.2$ \\
\hline
\end{tabular}

Mean $\pm \mathrm{SD},{ }^{*} \mathrm{p}<0.05,{ }^{* *} \mathrm{p}<0.01, \mathrm{FVC}$ : forced vital capacity, $\mathrm{FEV}_{1}$ : forced expiratory volume in $1 \mathrm{~s}, \mathrm{MVV}$ : maximum voluntary ventilation

data reported for underweight women.

Some young women want to be slim, so they diet severely. We believe that severe diet can aggravate the condition of the lung and reduce pulmonary function and vital capacity.

In conclusion, our results indicate that low body weight is related to the reduction of vital capacity of women. The results also indicate that the maintenance of adequate body weight is always important for improving the vital capacity of women. Further studies are needed to clarify these findings.

\section{Acknowledgement}

This research was supported by a Kyung-sung University Research Grant in 2012.

\section{REFERENCES}

1) Després JP, Lemieux I, Prud'homme D: Treatment of obesity: need to focus on high risk abdominally obese patients. BMJ, 2001, 322: 716-720. [Medline] [CrossRef]

2) Peeters A, Barendregt JJ, Willekens F, et al.: Obesity in adulthood and its consequences for life expectancy: a life-table analysis. Ann Intern Med, 2003, 138: 24-32. [Medline]

3) Jeon JK, Lee JI: Obese children's self-efficiency feeling and health promotion behavior. J Kor Soc Phys Ther, 2002, 14: 115-134

4) Formiguera $X$, Cantón A: Obesity: epidemiology and clinical aspects. Best Pract Res Clin Gastroenterol, 2004, 18: 1125-1146. [Medline]

5) National Statistical Office: The distribution of obesity. 2001.

6) Yook YS, Shim JY: Analysis of eating behaviors and disorders among underweight group and normal weight group of physical university female students. Korean J Sport Psychol, 2009, 20: 185-193.

7) Fried LP, Tangen CM, Walston J, et al.: For the cardiovascular health study collaborative research group. Frailty in older adults: evidence for a phenotype. J Gerontol, 2001, 56A: M146-M156.

8) Alfonso DT, Howell RD, Caceres G, et al.: Total hip arthroplasty in the underweight. J Arthroplasty, 2008, 23: 956-959. [Medline] [CrossRef]

9) Baltopoulos G, Fildisis G, Karatzas S, et al.: Reference values and prediction equations for $\mathrm{FVC}$ and $\mathrm{FEV}_{1}$ in the Greek elderly. Lung, 2000, 178: 201-212. [Medline]

10) Miller MR, Hankinson J, Brusasco V, et al.: Standardization of spirometry. 
Eur Respir, 2005, 26: 319-338. [CrossRef]

11) Qazi IR, Jabeen S, Durrani AM: Maximum voluntary ventilation values in young kashmiri adults through electronic spirometery. JK Pract, 2001, 8 : $235-236$.

12) Kondrup J, Allison SP, Elia M, et al.: ESPEN Guideline for nutrition Screening 2002. Clin Nutr, 2003, 22: 415-421. [Medline] [CrossRef]

13) Elia M: The malnutrition advisory group consensus guidelines for the detection and management of malnutrition in the community. Br Nutr Found Nutr Bull, 2001, 26: 81-83.

14) Medical section of American Lung Association: Standardization of spirometry-1994 update. Am Rev Respir Dis, 1994, 152: 1107-1136.

15) Flegal KM, Graubard BI, Williamson DF, et al.: Excess deaths associated with underweight, overweight, and obesity. JAMA, 2005, 293: 1861-1867. [Medline] [CrossRef]

16) Buzby GP, Mullen JL, Matthews DC, et al.: Prognostic nutritional index in gastrointestinal surgery. Am J Surg, 1980, 139: 160-167. [Medline]
[CrossRef]

17) Broussard DL, Magnus JH: Risk assessment and screening for low bone mineral density in a multiethnic population of women and men: dose one approach fit all? Osteoporos Int, 2004, 15: 349-360. [Medline] [CrossRef]

18) Chen Y, Rennie D, Cormier YF: Waist circumference is associated with pulmonary function in normal-weight, overweight, and obese subjects. Am J Clin Nutr, 2007, 85: 35-39. [Medline]

19) Chen Y, Horne SL, Dosman JA: Body weight and weight gain related to pulmonary function decline in adults: a six year follow up study. Thorax, 1993, 48: 375-380. [Medline] [CrossRef]

20) Santana H, Zoico E, Turcato E, et al.: Relation between body composition, fat distribution, and lung function in elderly men. Am J Clin Nutr, 2001, 73: 827-831. [Medline]

21) Drumond SC, Fontes MJ, Assis I, et al.: Comparison of three sets of reference equations for spirometry in children and adolescents with distinct body mass indices. J Bras Pneumol, 2009, 35: 415-422. [Medline] 